\title{
Activist systems: Futuring with living models
}

International Journal of

Architectural Computing $1-15$

(C) The Author(s) 2016

Reprints and permissions: sagepub.co.uk/journalsPermissions.nav DOI: I0.1 I77/|478077|I6638946 jac.sagepub.com

@SAGE

\section{Stanislav Roudavski' and Gwyllim Jahn²}

\begin{abstract}
This article considers how computational simulation can be used to amplify imagination and make its effects sharable, persuasive and activist. It argues that this is not only possible but important for the future of design and introduces the concept of living models as a device that can express the futuring potential of such simulations. Developing this argument, the article explores whether, by postponing top-down rationalisms in favour of a 'methodological naiveté', designers can gain the capacity to uncover and engage with the unusual participants of the complex dynamic assemblages they aim to change. When designers collaborate with the agencies of the living models they deploy, the outcomes prove useful for the exploration of alternative values and worldviews. Explorations of this kind are significant because human designs need to improve their integrations with existing complex systems and are innovative in their ambition to see creative agency in non-human actors. In a practical demonstration of such approaches, the experiments in generative computation presented in this article illustrate that design creativity occurs through humans but not entirely because of them.
\end{abstract}

\section{Keywords}

speculative design, generative design, design activism, simulation, creative computing

\section{Design}

$[\mathrm{I}] \mathrm{t}$ is an unavoidable feature of our narratives about human-technological systems that we are always faced with a contested ambiguity between human and material causation. (p. 39) ${ }^{1}$

Design can mean 'designing of nothing' (p. 71), ${ }^{2}$ and this article uses this interpretation to highlight the outcomes of design that are to do with systemic changes rather than with material objects. Design can also mean meta-design, ${ }^{3}$ understood as a mode of politics that seeks to go beyond that which is commonly thought possible. The article deploys both of these interpretations to explore how incorporation of systems into design processes can help to construct novel paradigms.

Seeking to provide a description that distinguishes design from other domains, Krippendorff (p. 28) ${ }^{4}$ suggests that designers can be motivated by (1) 'challenges, troublesome conditions, problems, or conflicts that have escaped (re)solution'; (2) 'opportunities to change something for the better - not recognised by others - to

\footnotetext{
'Melbourne School of Design, The University of Melbourne, Melbourne, VIC, Australia

${ }^{2}$ School of Architecture and Design, RMIT University, Melbourne, VIC, Australia

Corresponding author:

Stanislav Roudavski, Melbourne School of Design, The University of Melbourne, Melbourne 30I0, VIC, Australia.

Email: stanislav.roudavski@cantab.net
} 
contribute to their own or other communities' lives'; and, finally, by (3) 'possibilities to introduce variations into the world that others may not dare to consider, creating something new and exciting - just as poets, painters, and composers do - aimlessly and for fun'. In response to this categorisation, this article examines how problems (point 1) and opportunities (point 2) can be addressed if explorations labelled as 'aimless' by Krippendorff's third category are instead appreciated as opportunities to redesign design itself. Within this endeavour of redesigning design, methods for exploration of alternative paradigms - especially of alternative futures - can be cast not as 'random mutations, without apparent purpose or plan' (p. 70) $)^{5}$ but as deliberate strategies of managing change.

The current need to redesign design stems from recognition that design can act as a defuturing force (p. 21) ${ }^{6}$ when employed for the service of the established - and unsustainable - consumer societies. While this recognition is comparatively recent, the need for reinvention of design is likely to remain permanent in the world of accelerating change. The project of such redesign requires an in-depth theoretical discussion that cannot fit into this article. Instead, the present text focuses on one increasingly influential approach and discusses the role of (computational) modelling as framed by the following conceptual moves: (1) from human to post-human, (2) from human-centred design to ontological design and (3) from creativity to metamorphosis.

\section{From human to post-human}

The first of these moves is an extension of Wodiczko's (p. 16) Interrogative Design manifesto that proposes 'to explore, discover, uncover, and expose the hidden dimensions of lived experience'. This article sympathises with this desire but is concerned about the limitations that are inherent to the concept of 'lived experience', especially when it is utilised as a horizon for design explorations. While the definition of the 'lived experience' is missing in Wodiczko's document, it is reasonable to presume that his manifesto refers to human experience. This anthropocentric goal of interrogative design limits the range of 'hidden dimensions' by failing to ask what it means to be human and how human agency integrates with agencies of other entities. Acceptance of the responsibility for the anthropocentrism's pervasive environmental impacts can arrive through the understanding of how the concept of human was invented. The relevant discourse on posthumanism, and its objective of 'going beyond humanism's limit(ations)' (p. 245), ${ }^{6}$ is well established and design practices can benefit from rethinking their objectives and methods to take this into account. One way to approach this rethinking is through the studies of the roles technology plays in human performance, and the suggestion here is that such studies can productively move from the invention and appraisal of tools to the analysis of humans enmeshed in technological ecologies.

The discussion of such milieus in the next section is preceded by two images (Figures 1 and 2). Together with the other figures (Figures 3-6) in the current section, these images are drawn from speculative projects and are deployed here as suggestive samples of possible effects. By contrast, the images used in the section on the Salt City project (Figures 7-9) later in the article illustrate a specific case-study and are supported by the narrative.

\section{From nature to naturalised artifice}

The previous section proposed to reconsider how the notion of human is linked to the concepts such as technology and environment. In turn, this section observes that technology and environment are linked in contemporary interpretations of nature. This nature emerges not as wilderness, but as sets of interactions that include technical and societal processes. As Fry remarks, ${ }^{8}$ “" [W] $]$ " now exist in two kinds of intertwining "natures": the biological and the technological. Both "natures" are governed by specific but inherently internal processes (over which "we" have very limited and diminishing control)' (Part II.6. Passing Figures of Technology). In these conditions of limited control, it is necessary to move from the instrumental accounts that describe technology by function to considerations of its ongoing autopoiesis. 


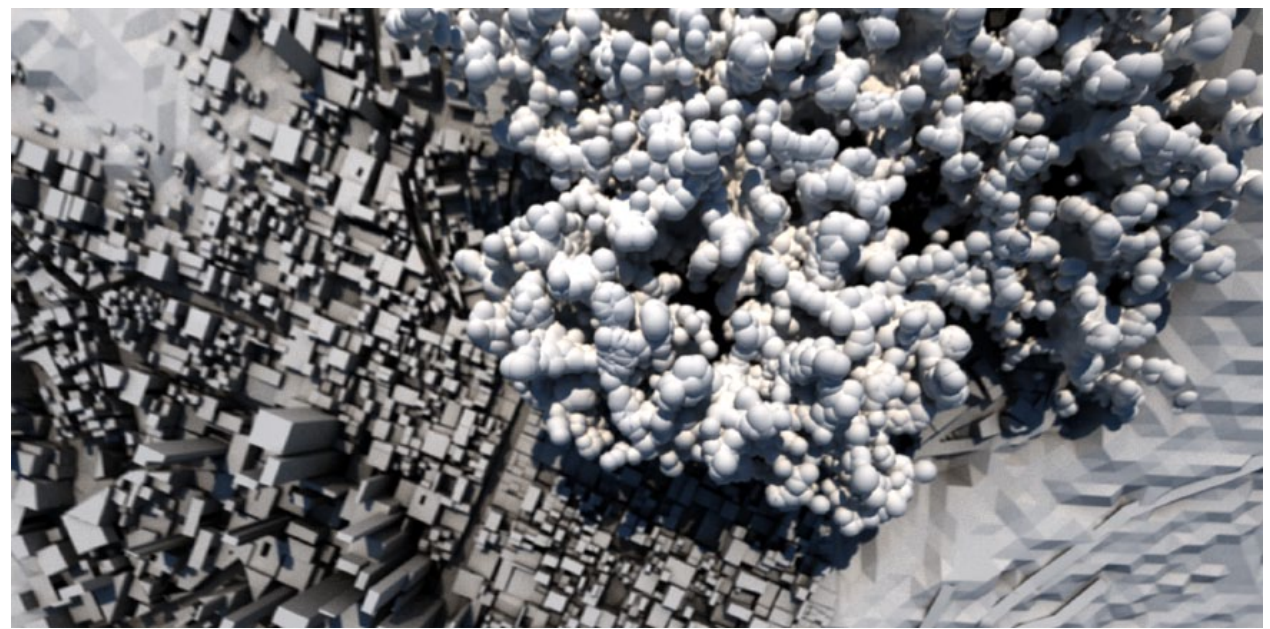

Figure I. The City beyond the City project provoked by showing consequences of design operations that are not fully under human control. It utilised procedural generation to expose difficulties inherent in translating planning rules into urban fabric.

Credits: Gwyllim Jahn and Tom Morgan.

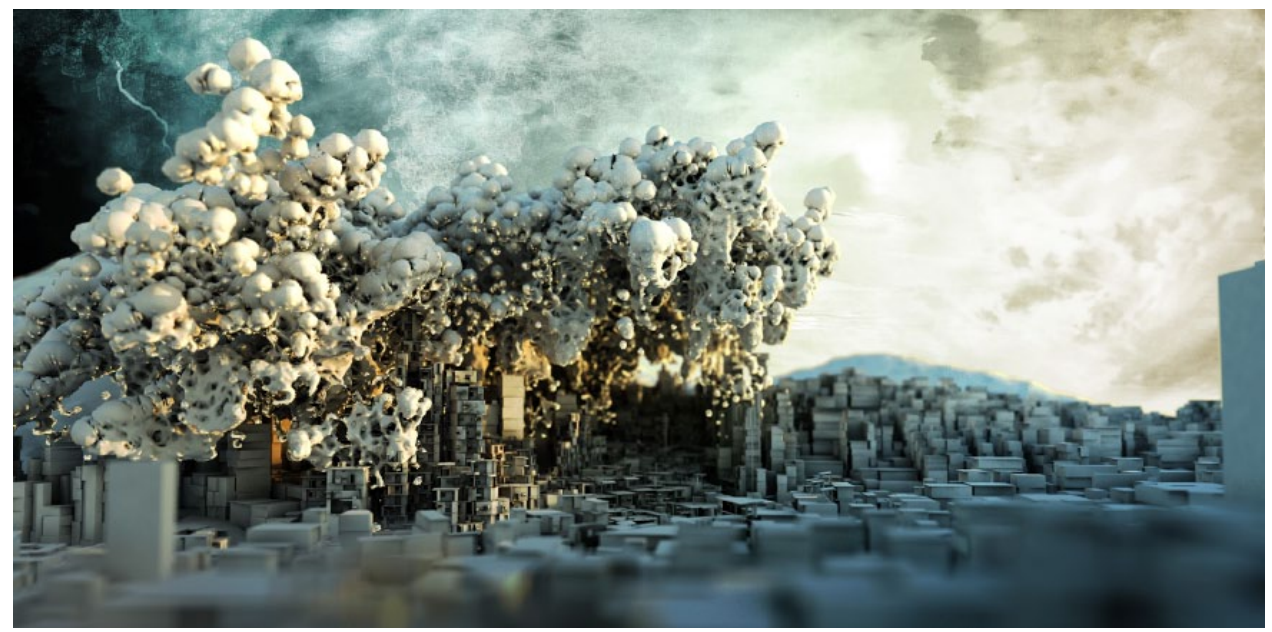

Figure 2. The City beyond the City project. Procedurally generated favela geometry shown next to an ambiguous mass that is a manifestation of internal logic responding to local conditions.

Credits: Gwyllim Jahn and Tom Morgan.

\section{From human-centred design to ontological design}

Given that all technology emerges through design, it is also useful to acknowledge that entities created through designing exert influence, in ways that extend well beyond specifications imposed by design briefs. The common view that designers work to solve problems for other people is becoming less influential. For example, Sanders and Stappers ${ }^{9}$ redescribe designers as user-centred creators informed by ethnographic research. However, ergonomic and human-centred design can also lead to defuturing, for example, when it 


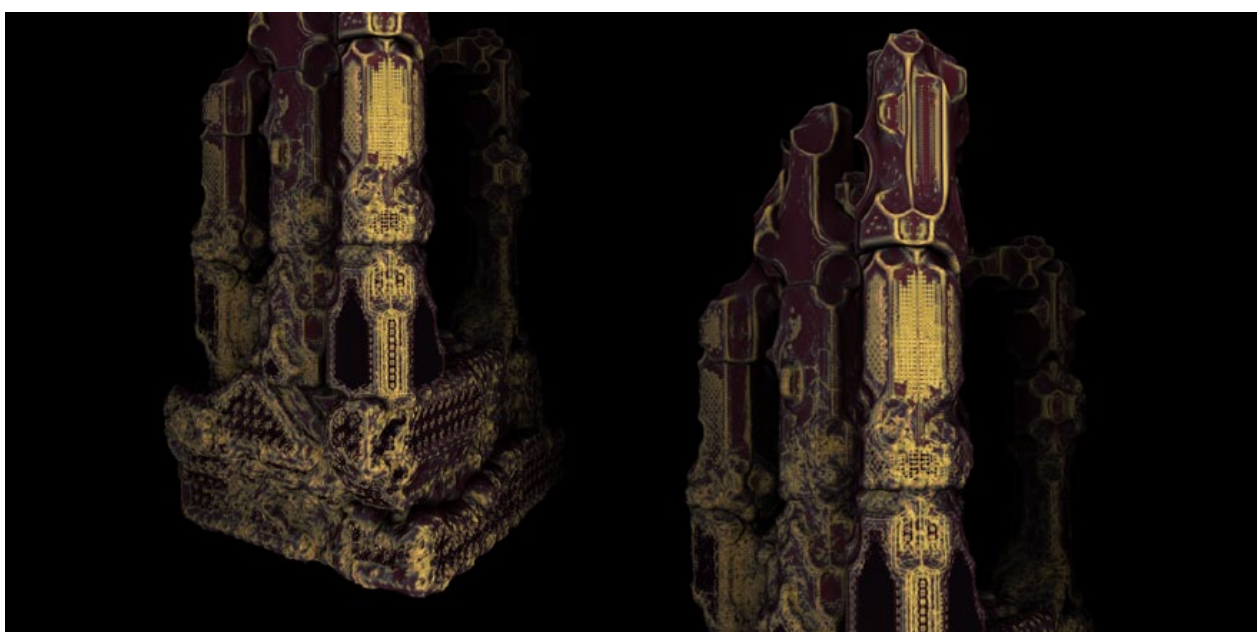

Figure 3. The Garden of Forking Paths project. A computational model originally devised in reference to a natural system produces architecture-like geometries. This perceptual confusion is a visual manifestation of technology posing as nature.

Credits: Gwyllim Jahn, Grant Trewella and Stephen Arnett.

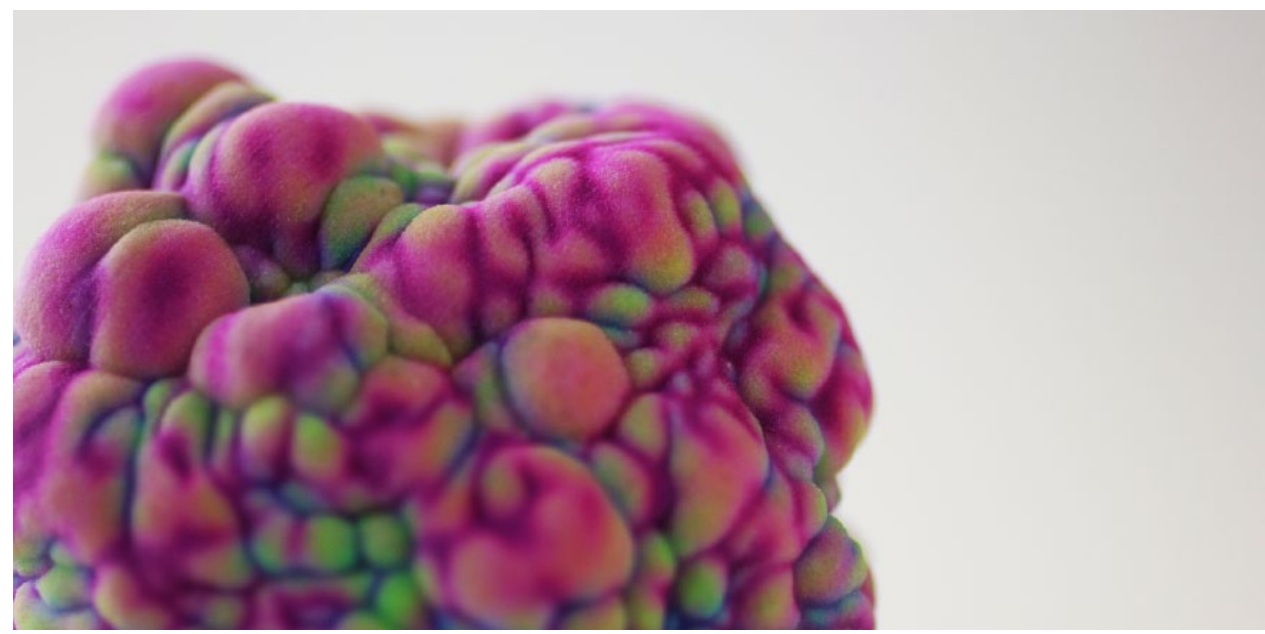

Figure 4. The Leviathan project. Another example of source confusion. In this case, an abstract process that iteratively expresses curvature as colour, and then shifts geometry in response to colour, results in appearances that seem natural.

Credits: Gwyllim Jahn, Todd De Hoog and Mitchell Walker.

is employed as an agent of consumerism (pp. 53, 54). ${ }^{2}$ To move past understandings that are confined by instrumentalist needs or existing professional and disciplinary boundaries, designing needs to be reconsidered as an elemental, ontological practice (cf. 'ontological design', ${ }^{10}$ behaviour-steering technology, ${ }^{11}$ transformation design ${ }^{12}$ or persuasive technology (captology) ${ }^{13}$ ). 


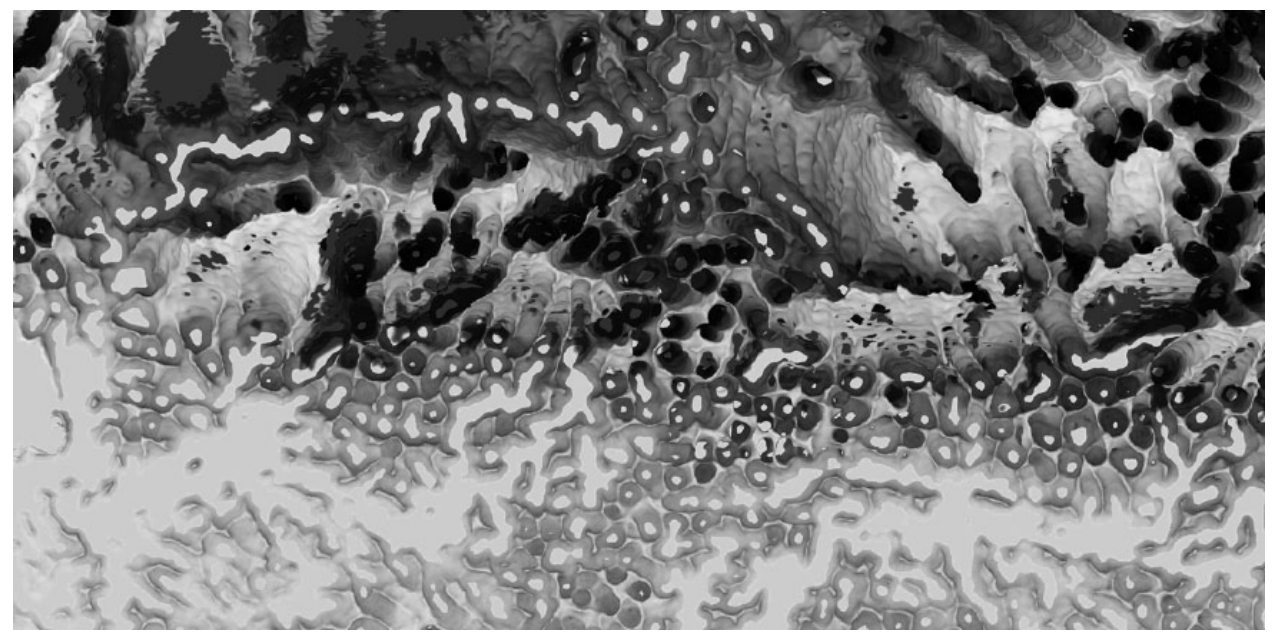

Figure 5. The Salt City project. A possible saline landscape produced by a particle-based generative model. This intermediate outcome is an example of prefiguration made of pre-existing computational ontologies and personal mastery. The many similar cells seen in this example become more flexibly differentiated in later versions (Figure 9) as the designers improve their capability to influence the system through learning about its possibility spaces. Credits: Gwyllim Jahn.
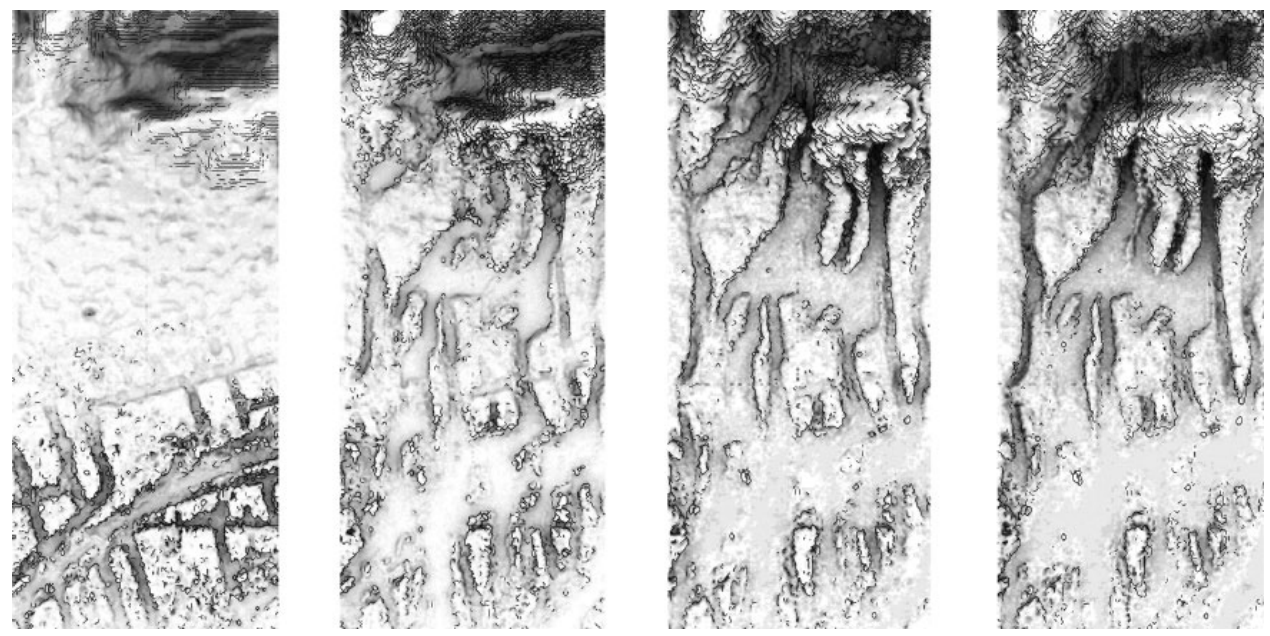

Figure 6. The Salt City project. Four consecutive states of the dynamic model showing gradual modification of landscape through processes of erosion and accumulation. The model is constrained to preserve the total amount of simulated material.

Credits: Gwyllim Jahn.

\section{From creativity to metamorphosis}

The recognition that practical design necessarily participates in ontological-design processes invites reconsideration of the concept of creativity by shifting away from the concept of creativity as an agency directed from within a human creator and out into the world. Even interpretations that emphasise the distributed 


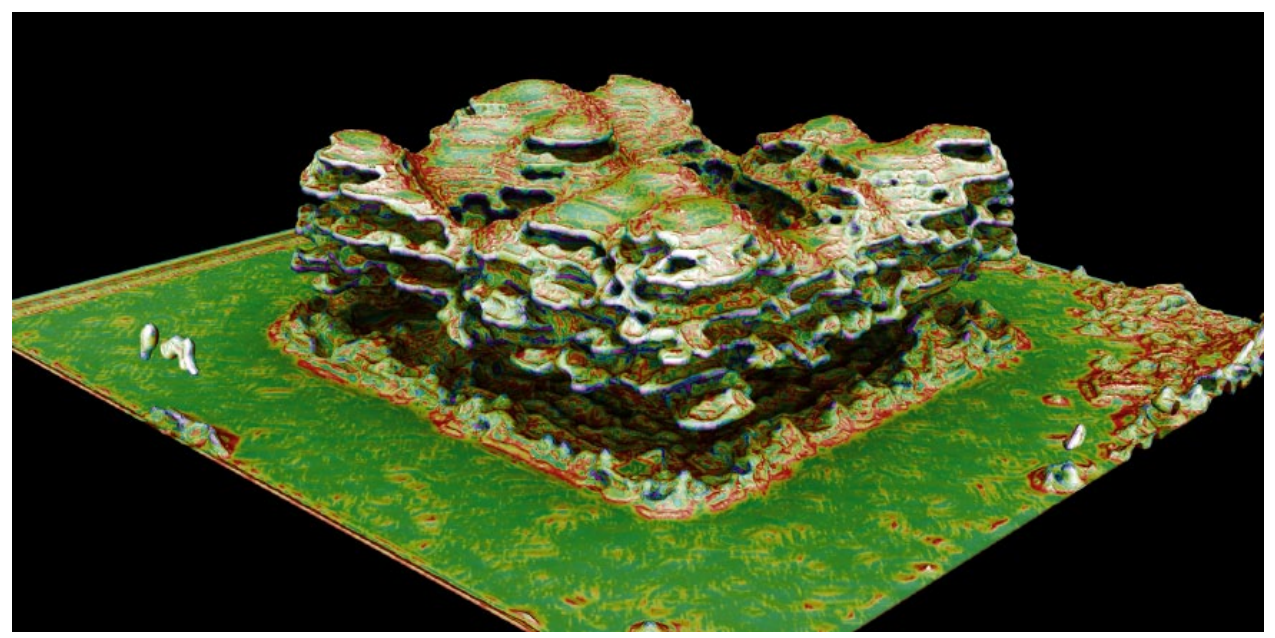

Figure 7. The Salt City project. Emergent geometric variation in a test model. The model exhibits features that may be interpreted as architectural or urban. For example, the articulation of forms within the centre suggests variable pressures of use; the threshold between at the edge of the surrounding 'landscape' suggests a public/private boundary; and the layers suggest human scale, walkability and a response to shading requirements. Geometry of this type is very hard to obtain through explicit modelling. For example, the transitions between the 'roof' of the model (the surface with red striations), the stacked recesses (blue strips) and the courtyard (at the centre of the image) involve a range of topological behaviours, such as splitting, extruding and folding. Because all of these features emerge from the dynamics of the model, they appear to be a coherent whole.

Credits: Gwyllim Jahn.

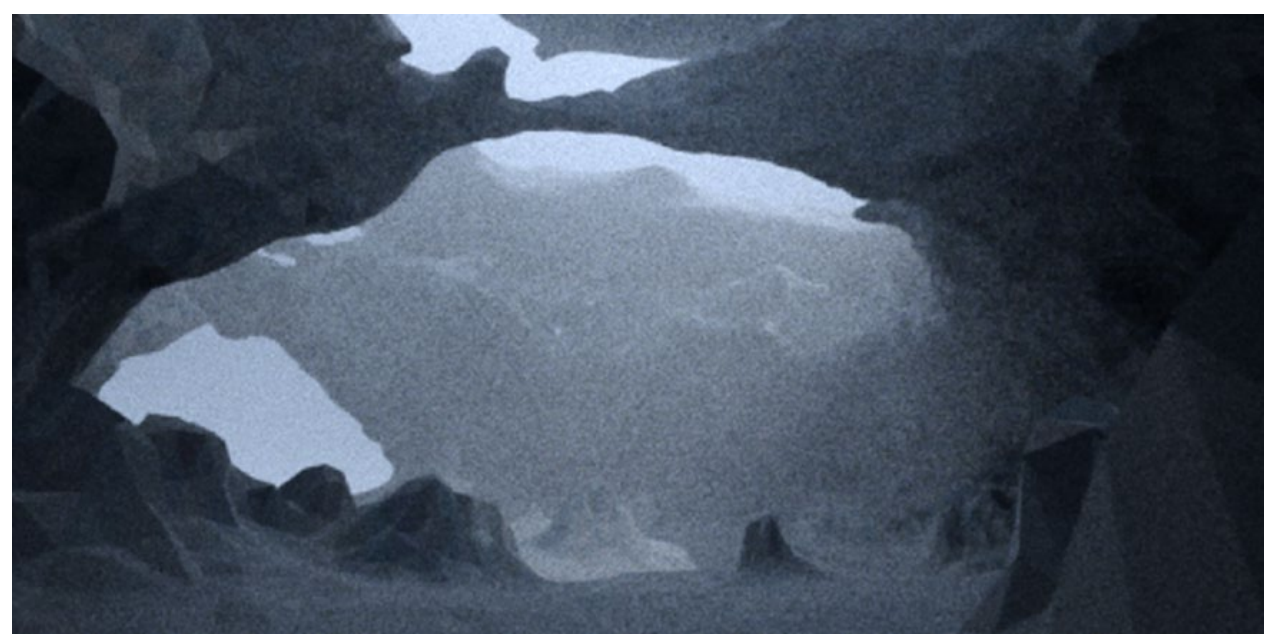

Figure 8. The Salt City project. A view of the landscape, also seen in Figure 9, showing pools, ridges, terraces and links that emerge from repeated interactions within the generative model. These features drive imaginative narratives of possible uses and social formations. For example, pools can host saline aquaculture, while the overarching links can be used as bridges. In turn, these narratives inform the design of the generative model as it is coaxed to preserve some features and encouraged to produce others.

Credits: Gwyllim Jahn and Kelvin Chai. 


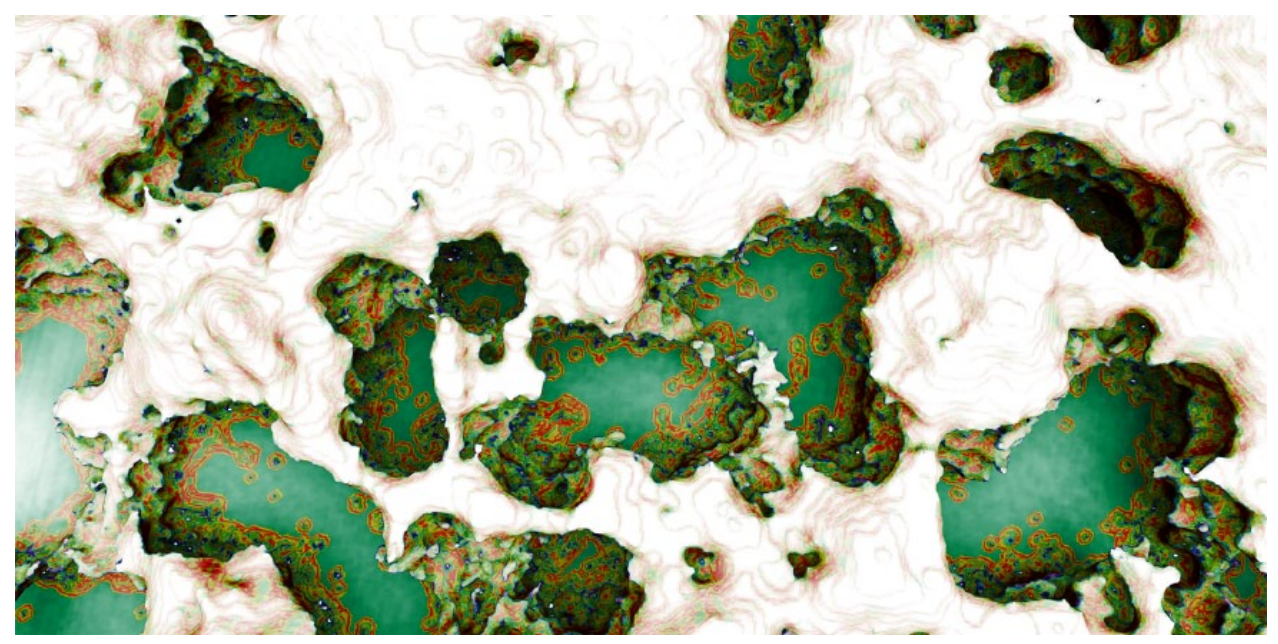

Figure 9. The Salt City project. A possible saline landscape. In the regions interpreted as 'agricultural landscape', the model self-organises into a network of deep recesses (blue-green pools). The model is in continuous flux, with large mounds becoming pools (small dark pockets in the white areas), bridges breaking into recesses (centre of the image) and hollows expanding to create overhanging geometry (areas showing clear shadows).

Credits: Gwyllim Jahn and Kelvin Chai.

character of creativity and acknowledge involvement of heterogeneous agents, including non-humans, prioritise focus on modifications introduced into the environment rather than on the inevitable simultaneous destruction of prior conditions. Instead, this article suggests the shift from the notion of creativity as the process of addition to its interpretation as the process of curation or - in other words - a shift from creativity to metamorphosis. This alternative way of seeing can adjust the orientation of design practice by exposing the need for methods with the ability to transform whole networks of habits and routines. ${ }^{14}$ In Fry's (p. 27) words, '[d] esign, so remade, would be inverted. It would have direction (time and orientation) as its primary objective, with form (objectified function) its secondary consideration'.

Wodiczko's 'lived experience' implies knowledge or skill acquired over time. As such, attention to 'lived experience' highlights trajectories already travelled. Explorations of this kind can be useful because without a conscious effort to question the structure of historical accumulations, it is difficult to extend them into possible futures. However, interrogation alone is insufficient in the task of imagining future alternatives, and the following section proposes an approach that focuses on the use of models.

\section{Modelling}

When we have found an acceptable theory, any model that may have led us to it can be thrown away. Kekulé is said to have arrived at the structure of the benzene ring after dreaming of a snake with its tail in its mouth, but no account of the snake appears in the textbooks of organic chemistry. (p. 7) $)^{15}$

We no longer progress from model to reality, but from model to model while acknowledging that both models are, in fact, real. (p. 19) ${ }^{16}$

Given that all models are partial, how can they illuminate possible futures of complex processes? What would an adequate type of modelling entail? Can models move beyond representation (p. 25) ${ }^{17}$ and be redirected towards the exploration of possibility spaces? 


\section{Critical making}

This article suggests that the answers to these questions can be proposed through the processes of making. Several relevant approaches have already been established. For example, conceptual art involves a critique of the materiality of the art object, a rejection of artistic practice as purely formal, a fusion of the work with its site and a focus on the way the work is distributed and interacts with the public and the ongoing discourse. ${ }^{18}$ Borrowing from this tradition, conceptual design offers

a critique of the present through the material embodiment of functions derived from alternative value systems. These 'material tales' are not utopian visions or blueprints - clear-cut modeling of the future is too didactic. Instead, they mix criticism with optimism to provide the 'complicated pleasure' found in other imaginative media such as film and literature, particularly those that explore boundaries between the real and the unreal. (p. xvii) ${ }^{19}$

Similarly, critical technical practice ${ }^{20}$ and reflective design ${ }^{21}$ consider ideologies that underlie the design of technical systems and help designers and users to think in new ways about the roles of technology. Likewise, the goal of 'critical making' is focused on 'using material production - making things - as part of an explicit practice of concept elaboration within the social study of technology' (p. 252). ${ }^{22}$ A close ally, critical making, sets out to understand 'the seeming disconnect between deterministic, conceptual understandings of the role of technology in social life, and the more material and nuanced understanding of how one relates to [it]' (p. 253). ${ }^{22}$ The typical process involves (1) review of literature and identification of ideas that can be explored through fabrication; (2) designing and building of technical prototypes by groups of stakeholders; and (3) an iterative process of reconfiguration, conversation and reflection.

This approach provides a useful precedent for considering the role of modelling in designing, but it has its limitations. For example, while seeking to emphasise the richness of design contexts, it focuses on human needs and desires, thus ignoring prefigurative agencies of non-human actors (the ontological nature of designing) or the consumer society's cultivated tendency to cast wants as needs. The failure to explicitly acknowledge the long-term and recursive characteristics of designing contributes to an impression of an apolitical attitude or what Arendt called a 'substitution of making for acting' (p. 229). ${ }^{23}$ Indeed, activities of the 'maker movement' caused concerns over military funding for its 'hackerspaces', resulting in calls for greater political awareness and critical reflection. ${ }^{24}$ However, as mentioned above, reflection alone is not enough for the construction of alternative imaginaries. To have broader impact, tinkering communities need to develop coherent toolsets including theories, methods, practices and specific tools. ${ }^{25}$

The desire to benefit from the approach set out as critical making while accounting for the limitations of its current conceptualisations leads to the key questions considered in this article: (1) can modelling function as 'critical modelling?' and (2) can it encourage appraisals of design actions motivated by alternative value systems?

\section{Models and design}

Before engaging with these questions, it is necessary to establish what this article sees as modelling. The typical understanding in architecture is that a model is a trial version 'of something which does not yet exist or perhaps can never fully exist'. It is also common to refer to a 'model dwelling', something that is proposed as a template for imitation. ${ }^{26}$ Architectural models usually exist as three-dimensional physical objects, but even this traditional form can support multiple types. They can be distinguished by techniques of construction and materials used: assembled, subtractive, additive, digital and so on. They can also be categorised by modes of engagement: portable, built for specific vantage points, immersive, reconfigurable et cetera. Models can fulfil a variety of roles in the design process or in other economic and social transactions such 
as education or marketing. Examples include conceptual models, massing models, analytical models (structural and environmental) or presentation and exhibition models. Models can seek to represent various entities and properties: site characteristics (relief, vegetation, etc.), views, action, geometry (mass, volume, surfaces and juxtapositions), sound, light, habitation, time/change (persistent models and models of historical slices) and experience (in full-scale prototypes).

The typical understanding of models in architecture is as objects of representation. ${ }^{27}$ As such, they are interpreted as instruments sustaining existing professional processes. ${ }^{28}$ Even when models are discussed as machines, these machines are understood as intrinsically passive objects controlled by humans and employed as 'thinking and defining mechanism[s] for understanding and demonstrating architectural concepts' (p. vii). ${ }^{29}$ As Downton ${ }^{30}$ suggests, models aid 'the processes and activities of designing. The intelligence and agency comes from the people involved in their making, use and understanding; they themselves have no agency' (p. 46).

If we continue with the thought that designing is about managing change, or metamorphosis, then models capable of capturing and exhibiting dynamic actualisations of relationships become more valuable. Computational techniques with their capacity to perform actions automatically are particularly suitable for the construction of such models. Indeed, various computer-supported models that attempt to describe organisations of elements or constraints are already in use in architecture. Such models include, for example, parametric/associative modelling or building information modelling and associated multi-dimensional models of construction processes. These models facilitate change management by standardising computational building blocks and providing sequential processes for the production of geometry and fabrication. However, such models are also intended as augmentations of existing professional processes and are, as such, bounded by the pre-existing habituses of their users.

By contrast, the approach developed in this article seeks to explore generative capabilities of models including their capacities to challenge established ways of thinking and working while still allowing 'marvel, wonder, astonishment, and surprise into the design process' (p. 2). ${ }^{29}$

As shown in a collaborative volume edited by Morgan and Morrison, ${ }^{31}$ models play a variety of roles in the sciences: they are used in the development, exploration and application of theories as well as in measurement methods. They also provide instruments for using scientific concepts to intervene in the world. Fishwick ${ }^{32}$ agrees that models are there to 'mediate between humans and phenomena' (p. 1). These uses go beyond the representation-oriented deployment, and the suggestion here is that architectural models can help designers in a similar way.

To allow models a greater agency in the design process, this article suggests a focus on their existence as crafted entities. More readily associated with design or making, craft is also essential in making scientific experiments but often goes unrecognised because of the tacit nature of its knowledge. ${ }^{33}$ This focus on craft seems promising in relation to the agency of models because craftsmanship implies direct and sustained engagements that help to develop nuanced understandings and relationships not attainable in any other way.

\section{Model craft}

Craft can be thought of as one of the horizons in a varied field of modern artistic practice (p. 2). ${ }^{34}$ Seen as such, it is not a classification of objects but a way of doing things, 'an approach, an attitude, or a habit of action' (p. 4) ) $^{34}$ or - alternatively - 'a set of concerns implicated across many types of cultural production' (p. 3). ${ }^{35}$ Out of Adamson's principles of craft practices - for example, that the craft is supplemental rather than autonomous or that its focus is on material experience rather than on optical effects - the one that is most relevant to the present discussion is that craft is grounded in skill.

Dormer $^{36}$ defines craftspeople as those 
engaged in a practical activity where they are seen to be in control of their work. They are in control by virtue of possessing personal know-how that allows them to be masters or mistresses of the available technology, irrespective of whether it is a mould, a hand tool, an electrically driven machine or a computer. It is not craft as 'handcraft' that defines contemporary craftsmanship: it is craft as knowledge that empowers a maker to take charge of technology. (p. 140)

How does this notion of skill relate to the notion of model? How does one develop 'system skill', and what is its relationship to creative freedom or capabilities to involve heterogeneous sources of agency? Can one become crafty with software when (1) so much is predesigned, (2) so much is changing so quickly and (3) so many characteristics of generative models are implicit?

In contrast with Dormer who emphasises control, $\mathrm{Pye}^{37}$ understands craftsmanship as good workmanship and values 'the workmanship of risk' where 'the quality of the result is not predetermined, but depends on the judgment, dexterity, and care which the maker exercises as he works' (p. 11). Understood in this way, craft is about the demonstration of virtuosity and thus creation of value and capital, monetary, cultural or otherwise.

How do the ideas of craftsmanship as a selfless pursuit of quality or craftsmanship as risk-taking align with the ideas of modesty, sustainment and ontological design, given their high costs? What does this type of investment buy apart from the magic of a virtuoso display or subjective aesthetics? Without suggesting that this article can resolve these large questions, the subsequent discussion offers a particular case-study that attempts to think about critical making and the redirective potential of computational models through craft, understood as skilful, gradual and collective acquisition of tacit knowledge. ${ }^{38}$

\section{Salt City modelling}

Issues of generative modelling for architectural (redirective) design can be exemplified through the Salt City project by Gwyllim Jahn and Tom Morgan. Salt City was a submission to the 2014 FuturArc Prize urban design competition 'Water and the City'. The brief called for 'a new vision of the water in the city' and suggested that such a vision 'might manifest itself through new networks or infrastructure that deal with flows and loops. The goal is in part sufficiency (therefore survival); it is also the well-being of settlements and the ecological systems that we depend on' ${ }^{39}$

Motivations. Most of the submissions to the previous iterations of this competition presumed that existing structures were adequate to deal with large, complex problems, like those implied by the brief, and did not engage with overriding vectors of environmental change. Thus, the competition presented an opportunity for a contrasting work aiming to question whether environmental issues can be resolved by green capitalist policies, reactive solutions and established design practices.

Idea. The resulting project reflected a desire to transfer the narrative capabilities of generative approaches from small, sympathetic and specialised audiences to the broader public. This move demonstrates a change in thinking about the role of modelling from instrumental to redirective. In implementing this thinking, the project sought to explore the tension between the constraints suggested by the established trajectory of environmental change in the region and typical urban design practices. The goal was not to 'solve' these observed differences by proposing a compromise but to use them as the context that drives accumulating change. In the resulting generative model, natural phenomena emerge as urban entities and failed urban practice becomes landscape. The design process did not attempt to alleviate the systemic problems or pretended to resolve complex issues by optimising the outcomes in reference to a limited range of measurable metrics. Instead, the project sought to use the generative capabilities of a computational model to highlight the complexity and integrated, time-bound nature of the challenge. 
According to De Landa, ${ }^{40}$ the presence of gradients (thermal, gravitational, mechanical, chemical, social etc.) creates conditions for the emergence of self-organising structures. Generative architectural models can stage similarly emergent performances. This staging can cast relatively simple dynamic models as useful because they can invite attention to the 'simulation gap' (p. 129), ${ }^{41}$ especially where the effects of emergence are 'mechanism-independent' (p. 13). ${ }^{40}$ Such effects can serve as useful representations of a disappearing boundary between natural and artificial, inviting an appreciation of environments as complex, uncontrollable ecologies that can respond unpredictably to human attempts at creativity.

Project criteria. Accordingly, the ambition of the project was not to predict but to enable critical reflection and make the unimaginable imaginable. In this context, the valuable outcomes could take form of speculations on the process and its validity, appraisals of possible predictions and conjectures on the futuring/defuturing capabilities of designed entities, rather than discussions of plans, objects or their descriptions. To achieve this, the project sought to

- Obtain geometry through the process of accumulation (by analogy with salt sedimentation). This geometric arrangement exhibited effects of long-term change including processes of habitation and erosion. Given that such processes are too slow to be perceived directly, the project had to show their outcomes as contrasting states with their history deducible from the images and suggested by coupled textual narratives.

- Relate the wilful actions of designers and the emergent effects of planning regulations by emphasising their systemic, dynamic and relational character. The project used generative computational models to highlight the outcomes that go beyond human capabilities for spatial imagination.

- Employ 'props' (p. 92) ${ }^{19}$ and 'real fictions' (p. 83) ${ }^{19}$ of imaginary (but possible) futures that can be entered and experienced. In an extension of the typically dry deployment of models in sciences, project used colours, proportions, detailing and other conventions of artistic, architectural and cinematic languages to invite intellectual and emotional engagement with computational models of these alternative realities.

- Construct a workflow that could accommodate a variety of scenarios across different scales, local conditions and as experienced by multiple types of stakeholders.

Choice of model. Generative computational models suit such criteria because they allow designers to construct, express and explore dynamic relationships rather than simply assume that these relationships lead to known effects. The development of the computational model is then a mixture of rational evaluations against project criteria with the craft knowledge accumulated while working with such models in the past. To illustrate, the computational models of the project sought to

- Self-organise to exhibit features interpretable as alternative systems of urban development without relying on random, chaotic or top-down, human-designed forms (Figure 7);

- Express the consequences of the model's dynamics (Figures 5, 6 and 9);

- Communicate developments that contrast with the typical urban patterns, such as the distributed urbanism of the project's site, and invite reconsiderations of the established planning methods (not represented in the included images).

Outcomes. The Salt City project resulted in an approach able to query typical narratives about urban development through computational models. The integration of models resulted in novel sequences of design development that could (1) begin with fictional narratives; (2) continue with real models; (3) switch to fictional or speculative architectural proposals; (4) apply real critique and comparative analysis to such proposals, 
deriving practically useful lessons; (5) proceed with re-imagining of the fictional narratives based on this analysis; and (6) conclude with descriptions of possible future alternatives (Figure 8).

Limitations. As all design projects, the Salt City project is developed with limited resources and could be improved through the involvement of additional, stakeholders, agencies, data sets and expertise. Of particular interest here are the two limitations that are specific to the utilisation of computational models. One is to do with the gap between what one wants to have modelled and what can be modelled. This gap can be caused by limited computing power, limited understanding and limited availability of suitable formal recipes; the practical need for abstraction and simplification; and so on. Given that these limitations are, to various degrees, inherent to all 'models, simulations and computer experiments' 42 - or 'model experiments, virtual experiments and virtually experiments' ${ }^{43}$ - it is important to conceptualise and test their role in the design process. In turn, these interpretative activities can suffer from another limitation that is to do with the need to translate the underlying ontologies and data of the models into messages that are meaningful for human audiences, although this article seeks to convert this limitation into a strength through the construction of 'model stories' that can extend past technical or conceptual constraints.

\section{Model stories}

Given that in this article's interpretation models are dynamic systems, model stories are similar to 'system stories'. As suggested by Whitelaw 44 , 'a "system story" is a translation or narration of the processual structures, ontology, entities and relations in a software system' (p. 140). He argues that stories can serve as useful devices for 'opening up these systems to discussion and critique' That is, while such stories are subjective and contingent, they can expose the implications of formal systems and thus contribute to 'generative art criticism'.

In this ambition to 'do more than make images of complex systems', to 'tinker critically with the systems themselves, then set them running, [achieving] possible worlds' (p. 152), ${ }^{44}$ might “critically generative' art projects rather conceal the system stories already at work in our contemporary world than uncover these narratives?' asks Inke Arns in the introduction to Whitelaw's article (p. 136). ${ }^{44}$ In parallel with this concern, can generative approaches to architecture hope to produce alternative stories, especially given the unavoidable reliance on ready mathematical and computational recipes? In Arns' words, would not these system stories remain 'system immanent - precisely because the solutions [they offer] are software based?'

One way 'to connect - critically, prospectively, speculatively - entities and relations within the system, with entities and relations outside it' (p. 140) ${ }^{44}$ is to couple the system stories with other narratives. For example, both The City beyond the City (Figures 1 and 2) and Salt City (Figures 5-9) projects extended the range of critical expression of model stories by coupling them with potentially disagreeing narratives not tackled by their ontologies. Through this approach, the creation of system stories becomes a composite process that combines learning from a model with an imaginary (or actual) dialogue with a wider range of stakeholders. In the case of the city projects, the system-derived affordances, intuitions and material effects interrelated with contemporaneous discussions around climate or disaster politics as well as with attitudes and practices of policy-makers and urbanists.

\section{Living models}

The next step in the quest to expose the roles of models is to ask whether they are equivalent to systems as it is presumed by the discussion of system stories above. The notion of system emphasises machinic interactions. How can one step from that abstract level into the contexts that engage with cultural expressions such as poetry, where irony, sympathy, absurdity, anger, beauty and sadness are not distracting side effects but valuable entities? How can one breach the gap between systems and living societies? 
Modelling can modify the worlds by making ideas possible, persuasive or repulsive. It is also convincing that through the use of tools, such as models,

it is not simply that the craft worker has 'superior' manipulative skills than other people, nor that they are just 'better' at using their hands than other people, but rather that the craft worker has a different view of the world and the artefacts it contains. (p. 52) (5 $^{5}$

In other words, designing modifies not only the world but also its designers. ${ }^{8}$

In this context, modelling can be seen not only as a lens but also as a technique for extending and changing abilities, becoming cyborg. As such, modelling emerges as an integral part of broader situations, an agent of living ecologies. The existing approach of critical making 'emphasizes the shared acts of making rather than the evocative object' (p. 153). ${ }^{22}$ This article similarly suggests that the act of making and the constructive processes of learning are at the centre of the modelling process along with the conceptual outcomes such as data, evidence or meanings. Such transformational outcomes cannot be readily reduced to natural languages, mathematics or code. Consequently, the agency of models in design is not only as evocative objects but also as acting (living) elements of techno-social ecologies that cannot be 'played', 'run', or 'performed' without such models in place. As participants of this kind, models become valuable as agents of change: not only as evidential artefacts, computational processes or system ontologies but also as living performances that manipulate relationships or - in other words - redesign design.

\section{Activist models, activist systems}

[Y]ou confuse two things: solving a problem and stating a problem correctly. It is only the second that is obligatory for the artist. (Chekhov, in a letter from 27 October 1888, while agreeing that artists need to adopt a reflective attitude to their work; translation by Constance Garnett).

' $[\mathrm{H}]$ ow can designers join things together again if they continue to be educated, and employed, as profitenhancing specialists, rather than ecologically and socially-minded generalists?' (p. 2$)^{46}$ One answer is that '[d]esigners $[\ldots]$ need to cocreate a discourse that enables everyone to understand things in a more holistic and relational way'. ${ }^{3}$ A variety of parallel approaches already exists, including, for example, design activism ${ }^{47}$ and meta-design. ${ }^{46,48}$

In an attempt to engage with the challenge of understanding architectural design in a more 'holistic and relational' way, this article discussed the role of models in the move from simulation to active collaboration and activism with the aim to transfer emphasis from sustainability to redesigning of design and from morphogenesis to redirection.

Redirective practices aim to reshape what a designing subject is, knows and does. Such practices seek to modify how people think about familiar or future phenomena. Given the problematic (unsustainable) nature of many established approaches, redirective efforts need to be challenging the very basic assumptions. This article suggests that computational models can be usefully employed for such purposes by contributing to the processes of ongoing learning, and thus advancing meta-design goals. As argued by Fischer (p. 89), ${ }^{49}[\mathrm{u}]$ ser-centered and participatory design approaches have focused primarily on activities taking place at design time', neglecting to support 'systems as living entities that can evolve over time'. In response, his interpretation of 'meta-design' is as 'a unique design approach concerned with opening up solution spaces rather than complete solutions (hence the prefix meta-) and aimed at creating social and technical infrastructures in which new forms of collaborative design can take place'.

This conceptualisation, while arriving from the field of software engineering, with different types of users and problems, is a suggestive approach with which to tackle the challenge of rethinking architecture as congregations of complexly interrelated ongoing performances. Complete and instantaneous solutions are 
impossible in such situations, especially when the challenge is that of redesigning the design practices and the designers themselves. Instead, methods of change should be gradual: accumulating expertise; constructing demonstrators; building evidence, developing workflows, establishing concepts, building communities and sharing knowledge. The artefacts, processes and systems discussed in this article should be seen as possible contributions to such practices; as manifestations of possibilities, rather than as self-standing objects, interesting thought they might be.

\section{Declaration of conflicting interests}

The author(s) declared no potential conflicts of interest with respect to the research, authorship and/or publication of this article.

\section{Funding}

The author(s) received no financial support for the research, authorship and/or publication of this article.

\section{References}

1. Galison PL. An Accident of History. In: Galison P and Roland A (eds) Atmospheric flight in the twentieth century. Dordrecht: Kluwer, 2000, pp. 3-44.

2. Fry T. Design futuring: sustainability, ethics and new practice. Oxford: Berg, 2008.

3. Wood J. Design for micro-utopias: making the unthinkable possible. Aldershot: Gower, 2007.

4. Krippendorff K. The semantic turn: a new foundation for design. Boca Raton, FL; London; New York: Taylor \& Francis CRC, 2006.

5. Krippendorff K. Design research, an oxymoron? In: Michel R (ed.) Design research now: essays and selected projects. London; Basel: Birkhäuser, 2007, pp. 67-80.

6. Fry T. Design as politics. Oxford: Berg, 2011.

7. Wodiczko K. Interrogative design. In: Wodiczko K (ed.) Critical vehicles: writings, projects, interviews. Cambridge, MA; London: MIT Press, 1999, pp. 16-17.

8. Fry T. Becoming human by design. London: Berg, 2012.

9. Sanders L and Stappers PJ. Convivial toolbox: generative research for the front end of design. Amsterdam: BIS Publishers, 2012.

10. Willis A-M. Ontological design - laying the ground. In: Willis A-M (ed.) Design philosophy papers collection three. Ravensbourne: Team D/E/S Publications, 2007, pp. 80-98.

11. Jelsma J. Design of behaviour-steering technology. In: Proceedings of the international summer academy on technology studies: strategies of a sustainable product policy, Deutschlandsberg, AU, July 2000, pp. 121-132. Graz: IFZ.

12. Burns C, Cottam H, Vanstone C, et al. RED paper 02: transformation design. London: Design Council, 2006.

13. Fogg BJ. Persuasive technology: using computers to change what we think and do. Amsterdam; Boston, MA: Morgan-Kaufmann, 2003.

14. Bourdieu P. The logic of practice. Stanford, CA: Stanford University Press, 1990.

15. Hesse MB. Models and analogies in science. Notre Dame, IN: University of Notre Dame Press, 1966.

16. Eliasson O. Models are real. In: Abruzzo E, Ellingsen E and Solomon JD (eds) Models: 306090. New York: Princeton Architectural Press, 2007, pp. 19-25.

17. Zepke S. Art as abstract machine: ontology and aesthetics in Deleuze and Guattari. New York; London: Routledge, 2005.

18. Alberro A. Reconsidering conceptual art, 1966-1977. In: Alberro A and Stimson B (eds) Conceptual art: a critical anthology. Cambridge, MA: MIT Press, 1999, pp. xvi-xxxvii.

19. Dunne A. Hertzian tales: electronic products, aesthetic experience and critical design. Cambridge, MA; London: MIT, 2005.

20. Agre PE. Toward a critical technical practice: lessons learned in trying to reform AI. In: Bowker G, Gasser L, Star $\mathrm{L}$, et al. (eds) Bridging the great divide: social science, technical systems, and cooperative work. Hillsdale, NJ: Lawrence Erlbaum Associates, 1997, pp. 131-158.

21. Sengers P, Boehner K, David S, et al. Reflective design. In: Proceedings of the 4th decennial conference on critical computing: between sense and sensibility, Aarhus, 21-25 August 2005, pp. 49-58. New York: ACM. 
22. Ratto M. Critical making: conceptual and material studies in technology and social life. Inform Soc 2011; 27(4): 252-260.

23. Arendt H. The human condition. Chicago, IL: University of Chicago Press, 1998.

24. O'Leary A. Worries over defense department money for 'Hackerspaces', 2012, http://www.nytimes.com/2012/10/06/ us/worries-over-defense-dept-money-for-hackerspaces.html?_r=0

25. Kiem M. If political design changed anything they'd make it illegal: review essay on Carl DiSalvo's Adversarial Design. Des Philos Pap 2013; 11(1): 31-38.

26. Harbison R. Thirteen ways: theoretical investigations in architecture. Cambridge, MA: MIT Press, 1998.

27. Moon K., Modeling messages: the architect and the model. New York: Monacelli Press, 2005.

28. Burry M, Ostwald M, Downton P, et al. Homo faber: modelling architecture. Sydney, NSW, Australia: Archadia, 2007.

29. Smith AC. Architectural model as machine: a new view of models from antiquity to the present day. Oxford: Architectural Press, 2004.

30. Downton P. Temporality, representation and mechanic behaviours: model dialogues with the self, collaborators, clients and others. In: Burry M, Ostwald M, Downton P, et al. (eds) Homo faber: modelling architecture. Sydney, NSW, Australia: Archadia, 2007, pp. 42-49.

31. Morgan MS and Morrison M. Models as mediators: perspectives on natural and social sciences. Cambridge; New York: Cambridge University Press, 1999.

32. Fishwick PA. Handbook of dynamic system modeling. Boca Raton, FL; London: Chapman \& Hall/CRC, 2007.

33. Delamont S and Atkinson P. Doctoring uncertainty: mastering craft knowledge. Soc Stud Sci 2001; 31(1): 87-107.

34. Adamson G. Thinking through Craft. New York: Berg, 2007.

35. Adamson G. The craft reader. Oxford; New York: Berg, 2010.

36. Dormer P. Craft and the turing test for practical thinking. In: Dormer P (ed.) Culture of craft. Manchester; New York: Manchester University Press, 1997, pp. 137-158.

37. Pye DW. The nature and art of workmanship. Cambridge: Cambridge University Press, 1968.

38. Collins H. What is tacit knowledge? In: Schatzki TR, Knorr-Cetina KD and Savigny EV (eds) The practice turn in contemporary theory. London: Routledge2001, pp. 107-119.

39. FutureArc Prize. FutureArc prize 2014. Competition information | brief + prizes, http://www.futurarc.com/index. $\mathrm{cfm} /$ competitions/2014-fap/ (accessed 17 November 2015).

40. De Landa M. Philosophy and simulation: the emergence of synthetic reason. London; New York: Continuum, 2011.

41. Bogost I. Unit operations: an approach to videogame criticism. Cambridge, MA: MIT, 2006.

42. Keller EF. Models, simulation, and 'Computer Experiments'. In: Radder H (ed.) The philosophy of scientific experimentation. Pittsburgh, PA: University of Pittsburgh Press, 2003, pp. 198-215.

43. Morgan MS. Experiments without material intervention: model experiments, virtual experiments and virtually experiments. In: Radder H (ed.) The philosophy of scientific experimentation. Pittsburgh, PA: University of Pittsburgh Press, 2003, pp. 216-235.

44. Whitelaw M. System stories and model worlds: a critical approach to generative art. In: Goriounova O (ed.) Readme 100: temporary software art factory. Norderstedt: BoD, 2005, pp. 135-154.

45. Baber C. Cognition and tool use: forms of engagement in human and animal use of tools. New York; London: Taylor \& Francis, 2003.

46. Wood J. Changing the change: a fractal framework for metadesign. In: Cipolla C and Peruccio PP (eds) Changing the change: design, visions, proposals and tools. Turin: Allemandi, 2008, pp. 1-8.

47. Fuad-Luke A. Design activism: beautiful strangeness for a sustainable world. London; Sterling, VA: Earthscan, 2009.

48. Giaccardi E and Fischer G. Creativity and evolution: a metadesign perspective. Digit Creat 2008; 19(1): 19-32.

49. Fischer G. Meta-design: beyond user-centered and participatory design. In: Proceedings of the HCI international - human-computer interaction: theory and practice, Crete, 22-27 June 2003, pp. 88-92. Mahwah, NJ: Lawrence Erlbaum Associates. 


\section{University Library}

\section{- M M I N E R VA A gateway to Melbourne's research publications}

Minerva Access is the Institutional Repository of The University of Melbourne

Author/s:

ROUDAVSKI, S;JAHN, G

Title:

Activist systems: Futuring with living models

Date:

2016-06-01

Citation:

ROUDAVSKI, S. \& JAHN, G. (2016). Activist systems: Futuring with living models. The International Journal of Architectural Computing, 14 (2), pp.182-196. https:// doi.org/10.1177/1478077116638946.

Persistent Link:

http://hdl.handle.net/11343/92415 